\title{
Degree of coupling and coordination of eco-economic system and the influencing factors: a case study in Yanchi County, Ningxia Hui Autonomous Region, China
}

\author{
LU Huiling ${ }^{1}$, ZHOU Lihua $^{1,2^{*}}$, CHEN Yong $^{1}$, AN Yiwei ${ }^{1}$, HOU Caixia ${ }^{1}$ \\ ${ }^{1}$ Key Laboratory of Desert and Desertification, Northwest Institute of Eco-Environment and Resources, Chinese Academy of \\ Sciences, Lanzhou 730000, China; \\ ${ }^{2}$ Institutes of Science and Development, Chinese Academy of Sciences, Beijing 100190, China
}

\begin{abstract}
Based on the statistical data, we analyzed and evaluated the degree of coupling and coordination of the eco-economic system in Yanchi County for the period spanning from 1983 to 2014. The eco-economic system can be divided into socioeconomic and ecological sub-systems and their relationship can reveal the interaction state between the two sub-systems and help the local government to establish a coordinated development mode. An index system was constructed to assess the development of the two sub-systems before the evaluation of the degree of coupling and coordination. The principal component regression analysis was adopted to quantitatively assess the influences of natural, economic and social factors on the degree of coupling and coordination of the eco-economic system. Results showed that, from 1983 to 2014, the development trends of both sub-systems were increasing with the ecological sub-system having more fluctuations. The degree of coupling and coordination of the eco-economic system in the study area increased gradually from 1983 to 2014, but experienced five different development stages from the verge of disorder to favorable coordination. The development of the local social and economic conditions was the most important factor influencing the degree of coupling and coordination. The second most important factor was the financial support from the local government. In addition, the environment protection policies also played undeniable roles. Due to the diversity of the influence factors, the government should take comprehensive measures to promote the sustainable development of the eco-economic system.
\end{abstract}

Keywords: degree of coupling and coordination; eco-economic system; ecological sub-system; socioeconomic sub-system; Yanchi County

Citation: LU Huiling, ZHOU Lihua, CHEN Yong, AN Yiwei, HOU Caixia. 2017. Degree of coupling and coordination of eco-economic system and the influencing factors in Yanchi County, Ningxia Hui Autonomous Region, China. Journal of Arid Land, 9(3): 446-457. doi: 10.1007/s40333-017-0098-z

\section{Introduction}

An eco-economic system is an open dissipating structure system (Costanza et al., 1993; Pearce and Warford, 1993), which can be divided into the ecological and socioeconomic sub-systems. Human activity is the most important factor affecting the development of these systems and can change the development characteristics and evolutionary directions of an eco-economic system by adjusting the input and output of the material, energy, and information of the system (Ruth, 1995; De Groot et al., 2002; Hai et al., 2005). Since the industrial revolution, mankind has created

${ }^{*}$ Corresponding author: ZHOU Lihua (E-mail: lhzhou@1zb.ac.cn)

Received 2016-01-04; revised 2016-06-11; accepted 2017-04-13

(C) Xinjiang Institute of Ecology and Geography, Chinese Academy of Sciences, Science Press and Springer-Verlag Berlin Heidelberg 2017 
unprecedented material wealth; however, the sustainable development of the eco-economic system has been severely challenged by the wars and sanctions caused by resource competition as well as the frequent natural disasters (Li, 2011; Li and Luo, 2015). In this century, the contradiction between the environment quality and economic development has become the most critical social problem. It is necessary to establish an effective coordination mechanism between the socioeconomic and ecological sub-systems to explore comprehensive, balanced and sustainable development modes.

Evaluating the degree of coupling and coordination was often desired to analyze the interaction within systems because it is effective and concise when comparing the degree of coupling and coordination between socioeconomic and ecological sub-systems in different areas or in different periods within an area (Huang, 2015). In physics, coupling and coordination refer to two (or more) systems or movement forms that may influence each other through a variety of interactions (Wu and Niu, 2006; Li et al., 2012). An appropriate coupling and coordination can assure a health development of the eco-economic system (Wu and Zhang, 2008). Zhao (2006) defined the coupling and coordination of an eco-economic system as a process of forming a chain of causality, and the main performance of the interaction between the ecological and socioeconomic sub-systems is the pressure, carrying capacity and feedback. Zhang et al. (2007a) held that the essence of development is the interaction of regional support and development consumption circles, and the resources and environment systems can determine the threshold of the level of socioeconomic development. The interaction between the two circles promoted the regional coupling and coordination state showing a trend of spiral escalation.

The farming-pastoral zone of the northern China has various ecological functions, such as prevention of the desert encroachment and conservation of water and soils. However, the ecological and socioeconomic sub-systems are both fragile in this area. In recent decades, along with an increase in the human population and a corresponding increase in economic activities, the function of the regional eco-economic system and its coupling and coordination effects have been weakened and in some aspects even been lost. This seriously restricts the sustainable development of the regional eco-economic system (Zhang and Feng, 2006; Chen and Duan, 2009; Chen et al., 2014).

The analysis of the coupling and coordination relationship between the ecological and socioeconomic sub-systems was an effective way to evaluate the regional sustainable development. The existing studies on the coupling and coordination relationship of the eco-economic system in farming-pastoral zone only simply described the relationship, but did not explore the factors influencing the relationship. This study took Yanchi County as an example to measure the degree of coupling and coordination between the ecological and socioeconomic sub-systems and to analyze the factors affecting the degree of coupling and coordination. The findings can be reliable references to guide policymakers for realizing the sustainable development.

\section{Study area}

Yanchi County is located in the eastern Ningxia Hui Autonomous Region (NHAR), at the north rim of the farming-pastoral zone of northern China (Fig. 1; 37 $04^{\prime}-38^{\circ} 10^{\prime} \mathrm{N}, 106^{\circ} 30^{\prime}-107^{\circ} 47^{\prime} \mathrm{E}$; $1600 \mathrm{~m}$ a.s.l.). The county is characterized by a typical temperate continental climate. The mean annual precipitation is about $250-350 \mathrm{~mm}$. The landscapes in the county include eroded hills, grassland, desert steppe, and sand dunes. The dry grassland and desert steppe distribute from the southeast to the northwest. The natural grassland covers about $5600 \mathrm{~km}^{2}$, accounting for more than $64 \%$ of the county area. The vegetation coverage is about $40 \%-50 \%$. The strong wind and scarce precipitation make the county suffering extensive land desertification.

The county used to be one of the most impoverished counties and also one of the most desertification areas in NHAR because of the excessive overgrazing, reclamation, firewood mining, and inappropriate development over a long period of time under the vulnerable eco-environment. The county is known as the hometown of China's Tan sheep and also as an 
important source area of licorice products. Overgrazing and excessive licorice harvests have led to serious degradation and desertification of the grassland. In 1975, the desertification area was about $1370 \mathrm{~km}^{2}$, accounting for $19.2 \%$ of the county area. In 2000 , desertification area reached $3510 \mathrm{~km}^{2}$, accounting for $51.8 \%$ of the county area (Ma et al., 2009). On 1 November 2002, the government implemented the grazing prohibition policy and the ecological degradation was thus reversed to some extent.

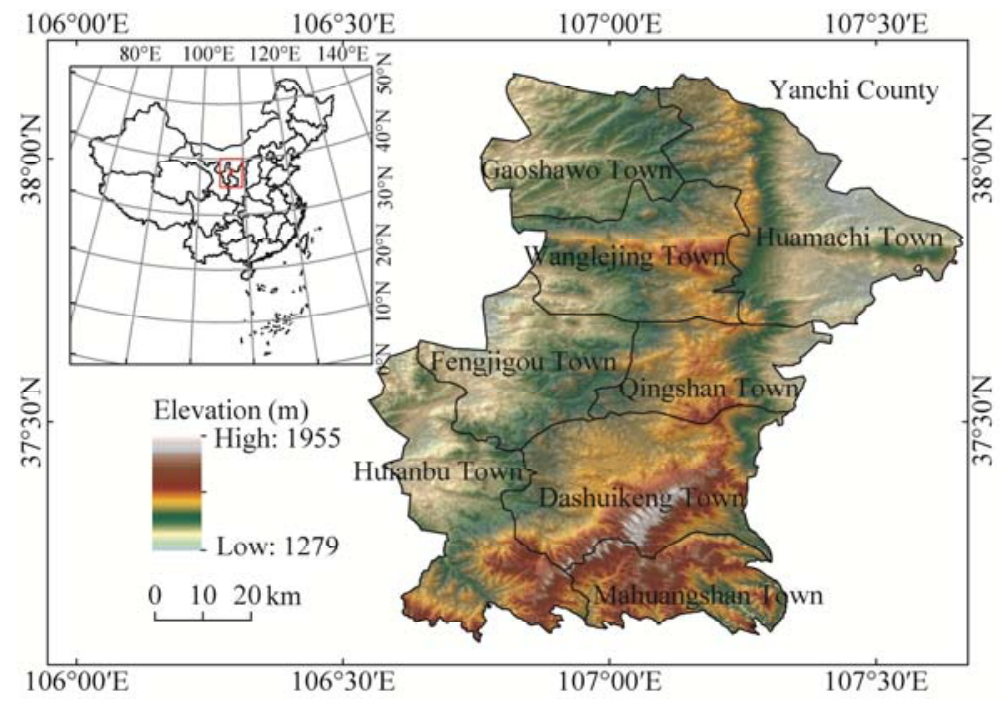

Fig. 1 Location of the study area

\section{Materials and methods}

\subsection{Data}

The social and economic data used in this study were from the statistical yearbook of Yanchi County (1949-2001; Yanchi Statistical Bureau), Yearbook of Yanchi (2002-2006; Ningxia People's Publishing House), Manual of Economy in Yanchi (2007-2014; Yanchi Statistical Bureau) and the Statistical Information Network of Yanchi (http://www.nxyctjj.gov.cn). The meteorological data were from the Yanchi Meteorological Bureau. The land data were provided by the Land and Resources Bureau. The missed data were obtained by interpolation.

\subsection{Methods}

The ecological and socioeconomic sub-systems interact with each other (Fig. 2). The ecological

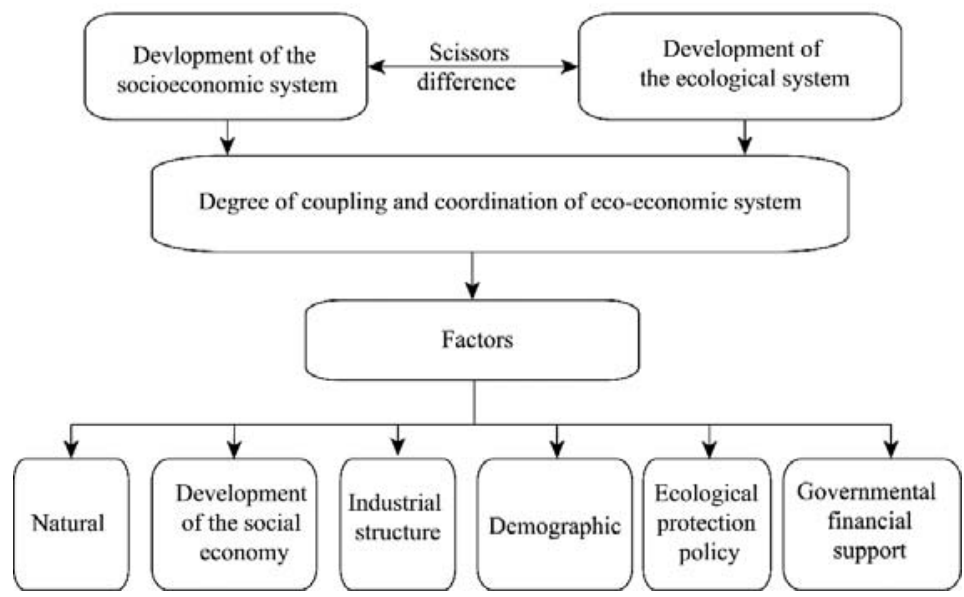

Fig. 2 Flowchart of research process 
sub-system plays an important role in supporting the development of the social economy while the socioeconomic system also has positive or negative effects on the ecological sub-system. To evaluate the degree of coupling and coordination between the two sub-systems, we first constructed an index system to value the development of the two sub-systems. We then used the coupling and coordination model and the scissors differences to analyze the degree of the coupling and coordination of the two sub-systems. Finally, we constructed another system to identify the factors influencing the degree of coupling and coordination.

\subsubsection{Development of the sub-systems}

People are the core element in the socioeconomic system. Population size and human activities can impact on the economic development. We selected the following indicators to evaluate the development of the socioeconomic system: total number of people, the sheep stock at the end of a year, urbanization rate, total retail sales of social consumer goods, and per capita GDP. In the ecological sub-system, the land is the most important element linking with human activities. There were more than $80 \%$ of population relying on farming and grazing in the study area. We chose the per capita land area (including farmland, forestland, grassland and water area), desertification index (desertification area/total regional area) and gale days to describe and evaluate the situation of the sub-system.

The weight of each index was determined by an objective-subjective combined method. The entropy and the expert evaluation methods were used to objectively and subjectively determine the weight of each index in the two sub-systems, respectively. Entropy method (Li and Jin, 2012; Wang et al., 2014) can be used to measure the uncertainty of a system and to judge the randomness and the disorder. And, the method can thus be used to determine the discrete degree of an index following the rule: the greater the degree of discrete value for an index is, the greater the influence of the index on the comprehensive evaluation. The extremum method was adopted to determine the standardized values for the original data in entropy method. For the subjective method, we selected 18 experts from research institutes and universities to assign a weight, a number between $0-1$, to each index according to the importance of the index in the sub-systems based on their the knowledge and experiences. Then we took the mean of the objective and subjective weights of each index as the final weight for the index (Table 1), which reflected not only the importance of an index but also the willingness of the decision makers (Wang and Li, 2006).

The weighted summation method was used to value the development degree of the socioeconomic $f(x)$ and ecological $g(y)$ sub-systems (Eq. 1).

$$
f(x)=\sum_{i=1}^{m} a_{i} x_{i} ; g(y)=\sum_{j=1}^{n} b_{j} y_{j} .
$$

Where $x_{i}$ and $y_{j}$ are standardized value of each index in the socioeconomic and ecological systems, respectively; $a_{i}$ and $b_{j}$ are the weights of the indices $(i=1,2, \ldots, m ; j=1,2, \ldots, n)$, and $m$ and $n$ are the number of indices in the socioeconomic and ecological sub-systems, respectively.

Table 1 Indices and their weights of the eco-economic system in Yanchi County

\begin{tabular}{lllll}
\hline \multicolumn{1}{c}{ Socioeconomic sub-system } & & & \multicolumn{2}{c}{ Ecological sub-system } \\
\cline { 1 - 2 } Index & Weight & & Index & 0.1832 \\
Total number of people & 0.0853 & & Desertification index & 0.3565 \\
Sheep stock at the end of the year & 0.1270 & & Gale days & 0.0826 \\
Population urbanization rate & 0.0942 & & Per capita farmland area & 0.1740 \\
Total retail sales of social consumer goods & 0.2862 & & Per capita forest area & 0.1175 \\
Per capita GDP & 0.4073 & & Per capita Grassland area & 0.0862 \\
& & & Per capita water area & 1.0000 \\
\hline
\end{tabular}




\subsubsection{Degree of coupling and coordination}

The coupling and coordination degree describes the relationship of the socioeconomic and ecological sub-systems in the process of the development.

Equation 2 shows the degree of coupling $(C)$ of the two sub-systems (Liao, 1999).

$$
C=\left\{f(x) \times g(y) /\left[\frac{f(x)+g(y)}{2}\right]^{2}\right\}^{1 / 2} .
$$

The degree of coupling can only express the strength of the interaction between the two sub-systems but cannot reflect the level of coordination of them. Therefore, we introduced the degree of coupling and coordination model. Equation 3 shows the comprehensive development degree $(T)$ of the eco-economic system; and Equation 4 presents the degree of coupling and coordination $(D)$ of the two sub-systems (Chen et al., 2013).

$$
\begin{gathered}
T=\frac{f(x)+g(y)}{2}, \\
D=\sqrt{C \times T} .
\end{gathered}
$$

$D$ indicates the relationship of the two sub-systems with a value between $0-1$. The higher the $D$ value is, the better the coordination will be. Table 2 presented the levels of the coupling and

\begin{tabular}{|c|c|c|c|}
\hline $\begin{array}{l}\text { Degree of coupling and } \\
\text { coordination }\end{array}$ & Level & $\begin{array}{l}\text { Degree of coupling and } \\
\text { coordination }\end{array}$ & Level \\
\hline $0.0000-0.0999$ & Extreme imbalance & $0.5000-0.5999$ & $\begin{array}{l}\text { Approximate } \\
\text { coordination }\end{array}$ \\
\hline $0.1000-0.1999$ & Serious imbalance & $0.6000-0.6999$ & Primary coordination \\
\hline $0.2000-0.2999$ & Moderate disorders & $0.7000-0.7999$ & Intermediate coordinate \\
\hline $0.3000-0.3999$ & Mild disorder & $0.8000-0.8999$ & Favorable coordination \\
\hline $0.4000-0.4999$ & On the verge of disorder & $0.9000-1.0000$ & Superior coordination \\
\hline
\end{tabular}
coordination.

Table 2 Type of coupling coordination and classification standard (Wang et al., 2009; Wang and Shi, 2013)

The scissors difference can further describe the developing-trend differences between the socioeconomic and ecological sub-systems. The angle $\alpha$ between the tangents of curves $\mathrm{f}^{\prime}(\mathrm{t})$ and $g^{\prime}(t)$ at a given moment $t_{0}$ was used to express the scissors difference. The larger the value $\alpha$ is, the greater the differences of the developing trends between the two sub-systems will be (Wang et al., 2009). Equations 5-7 described the scissors differences.

$$
\begin{gathered}
f^{\prime}(t)=d f / d t, \\
g^{\prime}(t)=d g / d t, \\
\alpha=\arctan \left|\frac{f^{\prime}(t)-g^{\prime}(t)}{1+f^{\prime}(t) g^{\prime}(t)}\right| \quad(0 \leq \alpha<\pi / 2) .
\end{gathered}
$$

3.2.3 Factors influencing the degree of coupling and coordination

Empirical researches showed that natural factors played an important role in this farming-pastoral zone. Du and Chen (2014) revealed that the degree of coupling and coordination in a system is actively affected by the industrial structure, environmental protection policies, and the development of energy infrastructure, the population, and technological progress of the region. Qian et al. (2012) and Li (2015) found that the level of basic education, external financial support, investment in scientific research, and level of employment also influence the degree of coupling and coordination. In addition, Zhang et al. (2007) reported the land-use policy is critical to the local sustainability and national ecological security in northern China. The factors identified in this study that affect the degree of coupling and coordination of the eco-economic system were natural environment, development of social economy, industrial structure, demography, government policy and financial support. The details are shown in Table 3. 
Table 3 Factors influencing the degree of coupling and coordination

\begin{tabular}{|c|c|}
\hline Category & Factor \\
\hline \multirow{4}{*}{ Social economy } & GDP \\
\hline & Deposit balances at the end of the year \\
\hline & Loan balances at the end of the year \\
\hline & Workers proportion in total population \\
\hline \multirow{2}{*}{ Demography } & Population growth rate \\
\hline & Number of full-time teachers \\
\hline \multirow{3}{*}{ Government financial support } & Investment of scientific research \\
\hline & Operating expense of education \\
\hline & Investment for farming, forestry, animal husbandry, side-line production and fishery \\
\hline \multirow{3}{*}{ Ecological protection policy } & Expenditure for energy conservation and environmental protection \\
\hline & Area of returning farmland to forest \\
\hline & Area of irrigated land \\
\hline \multirow{3}{*}{ Natural environment } & Net primary production (Zhou and Zhang, 1995) \\
\hline & Annual precipitation \\
\hline & Annual mean temperature \\
\hline \multirow{3}{*}{ Industrial structure } & Proportion of primary industry \\
\hline & Proportion of secondary industry \\
\hline & Proportion of tertiary industry \\
\hline
\end{tabular}

Principal component regression is a statistical analysis technique that uses the standard linear regression model for regressing the outcomes and uses principal component analysis for extracting principal components of independent variables first, and then estimating the unknown regression coefficients in the model. In this study, the degree of coupling and coordination of the two sub-systems was adopted as the dependent variable and the principal component regression was used to quantitatively assess the influences of natural, economic and social factors on the degree. Initially, we used principal component regression to extract the principal components from the independent variables. Then, taking each principal component as an independent variable, the regression coefficients could be obtained. Finally, the parameters of the original variables can be estimated based on the regression coefficients (Zhang and Dong, 2009). In addition, the multicollinearity between the independent variables was considered and $T$ (Eq. 8) was used to illustrate the tolerance since it is the most important statistics to illustrate the multicollinearity.

$$
T=1-R^{2}
$$

Where $R^{2}$ is the multiple correlation coefficient.

\section{Results and discussion}

\subsection{Degree of coupling and coordination}

The ecological and socioeconomic sub-systems presented different development trends over the study period 1983-2014 in Yanchi County (Fig. 3). The development of socioeconomic sub-system presented a relative stable increasing trend with two obvious stages. The comprehensive development function value $f(x)$ increased from 0.1704 in 1983 to 0.9717 in 2014 and the trend in 1983-2014 can be described by Equation 9.

$$
f(t)=0.00007 t^{3}-0.0022 t^{2}+0.0242 t+0.14, R^{2}=0.9957 .
$$

The annual growth rate was less than $10 \%$ with a mean value of 3.69\% during 1983-2003. Since 2004, the socioeconomic system development accelerated and the annual growth rate exceeded $10 \%$ with a mean value of $10.56 \%$. For the same period, the development of the ecological system was relatively slow and experienced a great volatility. The trend can be described by Equation 10 . 


$$
g(t)=0.00005 t^{3}-0.0019 t^{2}+0.0192 t+0.4179, R^{2}=0.5304 .
$$

Before 2010, the development of the ecological sub-system was slow and fluctuated with a mean growth rate of $1.23 \%$. Since 2010 , the growth rate increased rapidly and achieved a mean value of $11.17 \%$. A turning point appeared in 2007 for both sub-systems. The development level of the ecological sub-system was much higher than the socioeconomic sub-system before 2007. However, the development of socioeconomic sub-system exceeded the ecological sub-system after 2007.

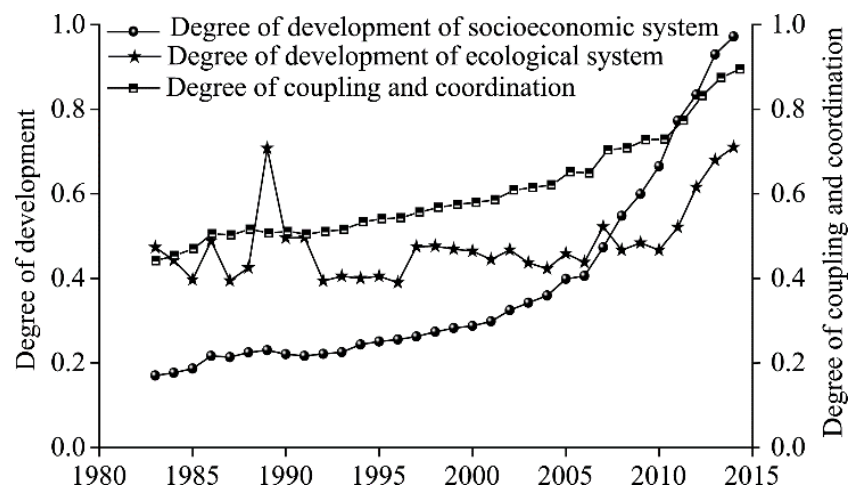

Fig. 3 Degree of coupling and coordination of the eco-economic system

In general, the coupling and coordination degree presented a positive and consistent improving trend over the study period. The degree of coupling and coordination rose from 0.4417 in 1983 to 0.8948 in 2014 with a mean value of 0.6035 , showing that the relationship of the two sub-systems has gradually become coordinated over the time. The variation of coupling and coordination degree can be divided into five stages. The first stage was 1983-1985 and the degree of coupling and coordination was smaller than 0.4999 , indicating that the eco-economic system was at the verge of disorder and showing an inter-conditioned relationship between the two sub-systems. In the second stage of 1986-2001, the degree value was 0.5000-0.5999, indicating that the eco-economic system entered a state of approximate coordination. In the third stage of $2002-$ 2006, the degree of coupling and coordination continuously improved and the state of the eco-ecological system reached the primary coordinated level. The fourth stage 2007-2011, the degree of coupling and coordination went up to the intermediate coordinated level and the relationship between the ecological and socioeconomic sub-systems became optimistic. After 2012, the degree of coupling and coordination was beyond 0.8 , indicating a favorable development coordination of the eco-economic system. However, the degree had not reached the superior coordination until 2014, meaning that there were rooms for further improvement.

The continuous developments of socioeconomic and ecological sub-systems were benefited from the grazing prohibition policy implemented in 2002 in Yanchi County. Feeding animals in barns reduced the damage to grasslands caused by livestocks (Chen et al., 2014), which helped in reversing the process of desertification (Yang, 2008). The development level of socioeconomic system lagged behind the ecological system before 2007. But, this trend was reversed after 2007. The large-scale breeding and changes to the farmers' sources of income under the new policy had no negative effect on local economic development and promoted the development of economy and improved environmental conditions (Su and Shang, 2013; Yang et al., 2014).

\subsection{Scissors difference between variation rates of the ecological and socioeconomic sub-systems}

As shown in Figure 4, the general trend of the scissors difference between the ecological and socioeconomic sub-systems increased over the study period 1983-2014, except with a slight decrease in the first few years (1983-1987). The scissors difference $(\alpha)$ dropped from $0.26^{\circ}$ to $0.20^{\circ}$ and reached the minimum in 1987 . The socioeconomic sub-system developed slowly while the ecological sub-system developed with large fluctuations and the gap between the two 
sub-systems gradually narrowed. However, after 1987, the scissors difference gradually increased and reached the maximum of $2.7^{\circ}$ in 2014. Although the two sub-systems were actively developing, the ecological sub-system developed far more slowly than the socioeconomic sub-system.

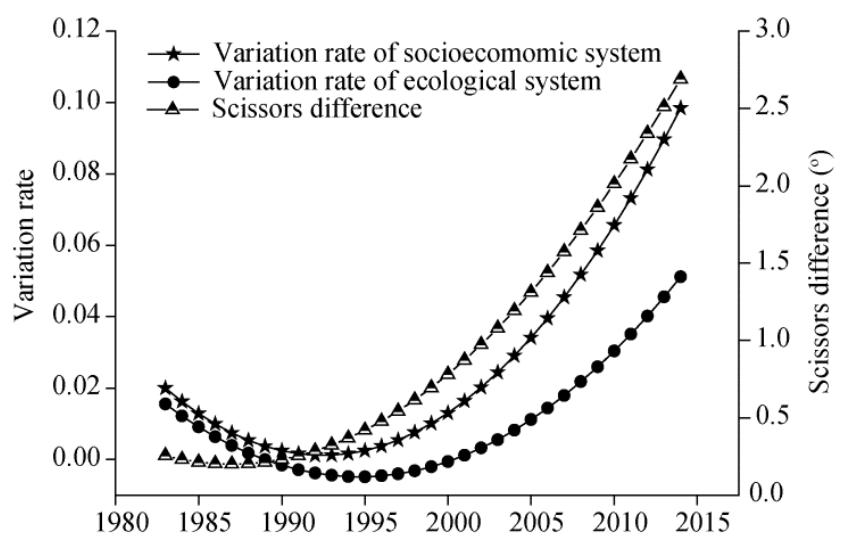

Fig. 4 Scissors difference between variation rates of the eco-economic systems

An increase of the scissors difference may cause problems, so the development speed of the socioeconomic sub-system should be adjusted to avoid a rapid deterioration of ecological sub-system. When the gap between the development levels of the two sub-systems exceeds a certain threshold, the coupling and coordination development of the eco-economic system would be impeded (Han et al., 2011), and the local sustainable development would be disrupted accordingly.

\subsection{Factors influencing the degree of coupling and coordination}

Based on the principle of that the eigenvalue of principal components was greater than 1 and the cumulative ratio of principal components summarizing the variance of original variables was greater than $80 \%$, we extracted four principal components. The first principal component contributed $46.927 \%$ of the variance; the total cumulative variances of the four principal components contributed $83.110 \%$, showing that the four principal components contained the majority of the information of the original variables. The principal component coefficient matrix can reflect the load of each principal component in each variable. We calculated the values of the four principal components and identified the four principal components as $\mathrm{F}_{1}-\mathrm{F}_{4}$ (Table 4).

Taking $\mathrm{F}_{1}-\mathrm{F}_{4}$ as independent variables and the degree of coupling and coordination as the dependent variable $(Y)$, we used stepwise regression analysis to calculate the coefficient of determination $\left(R^{2}\right)$ and the adjusted coefficient of determination $\left(R^{2}\right.$ adj $)$ for the model. The $R^{2}$ adj was 0.980 and the $F$ statistic was $1499.6(P<0.001)$, suggesting that a linear relationship between independent variables and dependent variable is significant. After stepwise regression analysis, only $\mathrm{F}_{1}$ remained in the model while other principal components were removed. The standardized regression coefficient of $\mathrm{F}_{1}$ was $0.990(t=38.73 ; P<0.001)$, indicating a significant linear relationship between the independent and dependent variables, namely, $Y=0.990 F_{1}$ (Table 5).

Based on the expression of principal component $F_{1}$, the regression coefficient of each variable can be determined. After ranking the regression coefficients by their numerical magnitude, the variable whose standardized regression coefficient reached the maximum was GDP. When GDP increased by one unit, the degree of coupling and coordination increased by 0.9575 units. The deposit balances at the end of the year also had a great influence on the degree of coupling and coordination (standardized regression coefficient $(\mathrm{SC}=0.9466)$ ), showing that when more funds were deposited in banks, the local residents would be richer, and degree of coupling and coordination of the eco-economic system could be higher. According to Maslow's needs-hierarchy theory, only if the material needs of people are satisfied could they have a greater spiritual pursuit. So, when residents had a richer life, they would pay more attention to 
environmental protection in Yanchi County. The influence of operating expense of education was also important $(\mathrm{SC}=0.9460)$. An increase of the investment in education can facilitate the coordinated development of the eco-economic system. The expenditures used for energy conservation and environmental protection also positively affected the degree of coupling and coordination $(\mathrm{SC}=0.9100)$. The proportion of primary industry had a negative influence on the degree of coupling and coordination $(\mathrm{SC}=0.9091)$, because the development of agriculture was often accompanied by the environment problems and therefore restricted the coordinated development of the eco-economic system. The proportion of secondary industry $(\mathrm{SC}=0.9066)$ showed that the development of secondary industry can promote the coordinated development of the two sub-systems.

Table 4 Coefficient matrix of the four principal components affecting the degree of coupling and coordination of the eco-economic system in Yanchi County

\begin{tabular}{|c|c|c|c|c|}
\hline \multirow{2}{*}{ Variable } & \multicolumn{4}{|c|}{ Principal component } \\
\hline & $\mathrm{F}_{1}$ & $\mathrm{~F}_{2}$ & $\mathrm{~F}_{3}$ & $\mathrm{~F}_{4}$ \\
\hline GDP & 0.967 & -0.226 & 0.025 & 0.013 \\
\hline Deposit balances at the end of the year & 0.956 & -0.232 & 0.050 & 0.052 \\
\hline Loan balances at the end of the year & 0.385 & -0.072 & -0.021 & 0.615 \\
\hline Workers proportion in total population & 0.810 & 0.403 & -0.080 & -0.223 \\
\hline Population growth rate & -0.612 & -0.542 & -0.189 & 0.078 \\
\hline Number of full-time teachers & 0.240 & 0.885 & 0.013 & 0.109 \\
\hline Investment of scientific research & 0.568 & -0.224 & -0.001 & 0.377 \\
\hline Operating expense of education & 0.956 & -0.192 & 0.002 & -0.071 \\
\hline $\begin{array}{l}\text { Investment for farming, forestry, animal } \\
\text { husbandry, side-line production and fishery }\end{array}$ & 0.771 & -0.284 & 0.062 & 0.112 \\
\hline $\begin{array}{l}\text { Expenditure for energy conservation and } \\
\text { environmental protection }\end{array}$ & 0.919 & -0.303 & 0.069 & 0.047 \\
\hline Area of returning farmland to forest & 0.060 & 0.475 & 0.385 & -0.369 \\
\hline Area of irrigated land & 0.879 & 0.253 & -0.135 & -0.270 \\
\hline Net primary production & 0.071 & -0.157 & 0.967 & -0.070 \\
\hline Annual precipitation & 0.088 & -0.132 & 0.971 & -0.045 \\
\hline Annual mean temperature & 0.219 & 0.453 & 0.259 & 0.626 \\
\hline Proportion of primary industry & -0.918 & -0.257 & 0.188 & 0.097 \\
\hline Proportion of secondary industry & 0.916 & -0.232 & -0.189 & -0.177 \\
\hline Proportion of tertiary industry & 0.058 & 0.948 & -0.009 & 0.147 \\
\hline
\end{tabular}

Table 5 Principal component regression of factors influencing the degree of coupling and coordination

\begin{tabular}{cccccc}
\hline Independent variable & $\mathrm{B}$ & $\mathrm{SE}$ & $\beta$ & $t$ & Sig. \\
\hline Constant & 0.604 & 0.003 & - & 198.600 & 0.000 \\
$F_{1}$ & 0.120 & 0.003 & -9.990 & 38.730 & 0.000 \\
$R^{2}$ & 0.980 & - & - & - & - \\
$R_{\text {adj }}^{2}$ & 0.980 & - & - & - & - \\
$F$ & $1499.60^{* * *}$ & - & - & - & -
\end{tabular}

Note: B, unstandardized coefficient. SE, Standard error of unstandardized coefficient. $\beta$, standardized coefficient.

The variables with a regression coefficient between $0.5-0.9$ included the workers proportion in total population, the population growth rate, the financial support from the government and the environmental policies. Among these variables, the proportion of workers in the total population had a positive influence on the degree of coupling and coordination, while the influence of the population growth rate was negative, mainly because the agricultural population was predominant in the county and a high population growth rate would create a great pressure on ecological sub-system. When the population growth rate increased by one unit, the degree of coupling and coordination dropped by 0.6058 units. The investment in farming, forestry, animal husbandry, 
side-line production and fisheries as well as the area of irrigated land also had positive effects on the degree of coupling and coordination. The government investment is conducive to agricultural modernization, with the goal of achieving a "win-win" for the development of both socioeconomic and ecological sub-systems. The standardized regression coefficients of the remaining variables were less than 0.5 and had relatively less influence.

According to the categories of the influence factors, facilitation of social and economic development to degree of coupling and coordination is most obvious with an influencing coefficient of 0.4253 ; the second is the government financial support with an influencing coefficient of 0.3129; environmental protection policy also has a strong effect on the degree of coupling and coordination with an influencing coefficient of 0.2435 ; industrial structure adjustment, demographic factors and natural factors slightly influence the degree of coupling and coordination with influencing coefficients of less than 0.1 . The increases of the proportion of secondary and tertiary industries were helpful to improve the degree of coupling and coordination, but the influence of the primary industry was negative because the development of secondary and tertiary industries can reduce the dependence of the agricultural population on land, which in turn can reduce the pressure on land resources and benefit environmental conditions. Otherwise, the level of agricultural modernization is relatively low in Yanchi County; therefore, the increase of proportion of primary industry is not conducive to the realization of the coupling and coordinated development. It indicates that industrial structure adjustment in Yanchi County has no obvious effect on coordination degree promotion. Among the demographic factors, the population growth rate was negatively correlated with the degree of coupling and coordination, and the influence of the number of full-time teachers was positive. However, the regression coefficient of the former was greater than that of the latter, causing the total effects of demographic factors to be negative. Yu (2006) pointed out that education plays a vital role in facilitating economic growth by accumulating human capital in a long-term. Zheng (2000) reported that education helped people setting up the correct view of the nature and enhanced the awareness of environmental protection. So, high population growth rate goes against to coupling and coordination but enhancing education is an effective method for promoting the degree of coupling and coordination. Li et al. (2014) found that natural geographical factors affect the degree of coupling and coordination, but the mechanism of this effect is quite complicated (Table $6)$.

Table 6 Factors influencing the degree of coupling and coordination of the eco-economic system in Yanchi County and their standardized regression coefficients

\begin{tabular}{lllllrl}
\hline \multicolumn{1}{c}{ Variable } & SC & & Variable & SC \\
\cline { 1 - 2 } GDP & 0.9575 & & $\begin{array}{l}\text { Expenditure for energy conservation } \\
\text { environmental protection }\end{array}$ & and & 0.9102 \\
Deposit balances at the end of the year & 0.9466 & & Area of returning farmland to forest & 0.0590 \\
Loan balances at the end of the year & 0.3812 & & Area of irrigated land & 0.8706 \\
Workers proportion in total population & 0.8015 & & Net primary production & 0.0704 \\
Population growth rate & -0.6058 & & Annual rainfall & 0.0874 \\
Number of full-time teachers & 0.2374 & & Annual mean temperature & 0.2166 \\
Investment of scientific research & 0.5622 & & Proportion of primary industry & -0.9091 \\
Operating expense of education & 0.9460 & & Proportion of secondary industry & 0.9066 \\
Investment for farming, forestry, animal & 0.7630 & & Proportion of tertiary industry & 0.0574 \\
husbandry, side-line production and fishery & & & &
\end{tabular}

Note: SC, standardized regression coefficient.

\section{Conclusions}

The degree of coupling and coordination between the socioeconomic and ecological sub-systems in Yanchi County presented a continuous improving trend over the study period 1983-2014. Local social and economic development, the government financial support, and environmental 
policies could help to promote the degree of coupling coordination while adjustments of the industrial structure, demographic and natural factors had less effect. As animal husbandry dominates the economy, the breeding method should be adjusted by replacing open field grazing with more efficient barn feeding; and the chain of the farming and animal husbandry industry should be extended to create a scale effect for the Tan sheep industry and to promote economic transformation. The resource utilization rate needs to be improved based on local conditions, especially for cultivated land and grassland. Lastly, the government should pay more attention to environmental management and allow Yanchi County government to play a leading role as a demonstration area in regional development. In the future, we should establish an index system with more information to analyze the coupling and coordination relationship of the eco-economic system and provide insight into the interaction mechanisms between ecological and socioeconomic sub-systems.

\section{Acknowledgments}

This research was supported by the National Natural Science Foundation of China (41471436, 41601587), the National Science and Technology Support Program of China (2015BAC06B01), the National Key Research and Development Program of China (2016YFC0500909) and the National Natural Science Foundation of China (41601587). The authors are very grateful to the anonymous reviewers and editors for their critical review and comments which helped to improve and clarify the manuscript.

\section{References}

Chen D L, Peng B F, Xiong J X. 2013. The coupling characteristics of eco-economic system in Dongting Lake Area. Scientia Geographica Sinica, 33(11): 1338-1346. (in Chinese)

Chen X H, Duan Z H. 2009. Changes in soil physical and chemical properties during reversal of desertification in Yanchi County of Ningxia Hui autonomous region, China. Environmental Geology, 57(5): 975-985.

Chen Y, Wang T, Zhou L H, et al. 2014. Effect of prohibiting grazing policy in northern China: a case study of Yanchi County. Environmental Earth Sciences, 72(1): 67-77.

Chen Y X, Dong S C, Li Z H, et al. 2014. A case study of agriculture eco-economic system based on emergy analysis: Wengniute-Kulun County in China. Ecological Economy, 30(4): 78-80, 94. (in Chinese)

Costanza R, Wainger L, Folke C, et al. 1993. Modeling complex ecological economic systems. BioScience, 43(8): 545-555.

De Groot R S, Wilson M A, Boumans R M J. 2002. A typology for the classification, description and valuation of ecosystem functions, goods and services. Ecological Economics, 41(3): 393-408.

Du Z L, Chen W J. 2014. Research on coordinated development of coal industry, regional economy and ecological environment in Xinjiang based on the coupling theory. Xinjiang State Farms Economy, (5): 37-41. (in Chinese)

Hai J B, Mu G H, Shi J T. 2005. Research on the techniques ecology flow couple with value flow dry-land ecosystem. Chinese Agricultural Science Bulletin, 21(11): 338-340. (in Chinese)

Han R L, Tong L J, Tong W M, et al. 2011. Coordinated evolvement of dynamic coupling between economic and environmental systems in Shenyang Metropolitan Area. Chinese Journal of Applied Ecology, 22(10): 2673-2680. (in Chinese)

Huang Z M. 2015. Research on spatio-temporal pattern of coupling characteristics of rural eco-economic system in Gannan Soviet Area. MSc Thesis. Nanchang: Jiangxi Normal University, 7-10. (in Chinese)

Li S, Luo X Q. 2015. Emergy assessment and sustainability of ecological-economic system using GIS in China. Acta Ecologica Sinica, 35(5): 160-167. (in Chinese)

Li X M, Jin P Y. 2012. Characteristics and spatial-temporal differences of urban human settlement environment in China. Scientia Geographica Sinica, 32(5): 521-529. (in Chinese)

Li X Y. 2011. Analysis of dynamic change and spatial difference of ecological and economic system in Shaanxi Province. Journal of Weinan Teachers University, 26(7): 76-79. (in Chinese)

Li Y F, Li Y, Zhou Y, et al. 2012. Investigation of a coupling model of coordination between urbanization and the environment. Journal of Environmental Management, 98: 127-133.

Li Y R, Wang J, Liu Y S, et al. 2014. Spatial pattern and influencing factors of the coordination development of industrialization, informatization, urbanization and agricultural modernization in China: a prefecture level exploratory spatial data analysis. Acta Geographica Sinica, 69(2): 199-212. (in Chinese)

Li Y Z. 2015. Research on "four modernizations" coupling coordination degree in Henan Province and its influencing factors. 
Journal of Henan Normal University (Philosophy and Social Sciences), 42(5): 36-41. (in Chinese)

Liao C B. 1999. Quantitative judgment and classification system for coordinated development of environment and economy-a case study of the city group in the Pearl River Delta. Tropical Geography, 19(2): 171-177. (in Chinese)

Ma Y H, Zhou L H, Zhu Y L, et al. 2009. Time series variation in the driving factors leading to land desertification in Yanchi County over the last 50 years. Arid Zone Research, 26(2): 249-254. (in Chinese)

Pearce D W, Warford J J. 1993. World without End: Economics, Environment, and Sustainable Development. Oxford: Oxford University Press, 135-142.

Qian L, Chen Z W, Xiao R Q. 2012. Study on China regional industrialization, urbanization and agricultural modernization coupling coordination degree and its influencing factors. Inquiry into Economic Issues, (11): 10-17. (in Chinese)

Ruth M. 1995. Information, order and knowledge in economic and ecological systems: implications for material and energy use. Ecological Economics, 13(2): 99-114.

Su F, Shang H Y. 2013. The impact of ecological compensation patters on livelihood strategy of farmers in Zhangye. Journal of Arid Land Resources and Environment, 27(2): 58-63. (in Chinese)

Wang H, Shi P J. 2013. Coordination degree of urbanization and land-water resources benefits of Wuwei City. Arid Land Geography, 36(5): 963-969. (in Chinese)

Wang M Q, Wang J D, Liu J S, et al. 2009. Dynamic coupling of ecological supporting capability and socioeconomic development of west Jilin Province. Chinese Journal of Applied Ecology, 20(1): 170-176. (in Chinese)

Wang Q S, Yuan X L, Cheng X X, et al. 2014. Coordinated development of energy, economy and environment subsystems-a case study. Ecological Indicators, 46: 514-523.

Wang Z X, Li Q X. 2006. An approach to integrate the final weights based on the subjective and objective weights. Communication on Applied Mathematics and Computation, 20(1):87-92. (in Chinese)

Wu W H, Niu S W. 2006. Evolutional analysis of coupling between population, resources and environment in Gansu Province. Chinese Journal of Population Science, (2): 81-86. (in Chinese)

Wu Y M, Zhang Y. 2008. Analyzing coupled regional economic growth and environmental conservation in China. Resources Science, 30(1): 25-30. (in Chinese)

Yang G. 2008. Study on dynamic change of landscape pattern and desertification in Yanchi County Based on $3 \mathrm{~S}$. PhD Dissertation. Beijing: Beijing Forestry University.

Yang Y, Hasi E, Du H S, et al. 2014. Impacts of land use change on ecosystem service value in Yanchi County of Ningxia based on RS and GIS. Research of Soil and Water Conservation, 21(5): 100-105. (in Chinese)

Yu C L. 2006. Investment structure in human capital and economic growth - endogenous economic growth analysis based on education capital and health capital. Journal of Finance and Economics, 32(10): 102-112.

Zhang F G, Liu Y S, Wang J Y. 2007a. Analysis of regional system couple state in rapid developing coastal region: a case study of Hainan Province. Resources Science, 29(1): 16-20. (in Chinese)

Zhang L X, Yang Z F, Chen G Q. 2007b. Emergy analysis of cropping-grazing system in Inner Mongolia Autonomous Region, China. Energy Policy, 35(7): 3843-3855.

Zhang W T, Dong W. 2009. Advanced Tutorials of SPSS Statistical Analysis. Beijing: Higher Education Press, 213-234. (in Chinese)

Zhang X J, Feng Z K. 2006. LUCC in farming pasture ecotonal areas based on RS and GIS - a case study of Yanchi County in Ningxia. Journal of Beijing Forestry University, 28(1): 32-38. (in Chinese)

Zhao X. 2006. The study on coupling relationship of ecology-economy system in Wudang of Guiyang. Journal of Guizhou Normal University (Natural Sciences), 24(3): 111-115. (in Chinese)

Zheng L H. 2000. Special role of education in environmental protection. Coastal Environment, (7): 17-18. (in Chinese)

Zhou G S, Zhang X S. 1995. A natural vegetation NPP model. Acta Phytoecologica Sinica, 19(3): 193-200. (in Chinese) 